\title{
COVID-19: Understanding the Board's Key Role During a Crisis
}

\author{
Joseph Astrachan (SC Johnson College of Business) \\ Andrew Keyt \\ Hermut Kormann (Zeppelin University) \\ Claudia Binz Astrachan (Lucerne University of Applied Sciences and Arts)
}

KEYWORDS: crisis management, Board of directors, Governance.

A board's oversight and guidance, based on the expertise, experience and personal qualities of its members, has always helped drive business success and survival. But now, as the COVID-19 pandemic shakes societies and economies around the globe, boards play an even more critical role. Companies that can tap their boards' crisis mitigation skills will likely have an edge over companies whose owners don't recognize the board's potential or can't encourage board members to step up.

For family businesses with many shareholders, the board's role is especially critical. The board can help build and preserve family commitment and continuity when tough decisions must be made. It can be a trusted expert about future prospects and difficult but necessary changes, and a respected arbiter of the many tradeoffs between family benefits and business survival and prosperity. The calming influence of the board can steer the family away from destructive behaviors that undermine the family and the business: emotional outbursts, inappropriate attempts to influence others, and more. Lastly, their impact can be long-lived if they serve as mentors to family business leaders and employees, and help them reflect on how they've handled and learned from difficult times.

The current pandemic is unprecedented in its impact. Companies must simultaneously think outside the box, develop a variety of plans that adequately respond to different scenarios, and use what they have effectively. This article describes the board's responsibilities in this current environment and proposes some ways that family businesses can leverage their board to help both the family and the business during a crisis.

\section{First Things First: Setting the Frame} An important first step, and one that requires the voice of all board members, is to define the assumptions under which people in the organization should plan and execute the measures proposed. These basic assumptions help family members understand what the business must do and the expected outcome, and will affect family commitment and cohesion.

\section{Duration \& Extent}

- The board agrees on their assessment (ideally based on reliable data and expert opinions) of how long the crisis will last (e.g., six, 12, or 18 months)?

- The board agrees on their assessment of the assumed shape of the curve (again, ideally based on reliable predictions) of the impact. This means plotting out when the crisis will peak, whether it will peak once or more, how much time will be in between peaks, when recovery can be expected, and how the company will prepare for all of it.

- The board acknowledges the reality of "delayed effect," which is a basic law of firefighting: The flames you see in this very moment are those that originated half an hour ago, and the fire an hour from now is exponentially worse.

\section{Business Model}

- The board evaluates whether a radical change in how business is done is needed in order to survive (e.g.,changing the customer base from restaurants to individual customers or a channel
Copyright $@ 2020$ The Authors. Entrepreneur \& Innovation Exchange is published at EIX.org. This is an open access article under the terms of the Creative Commons Attribution-NoDerivs License, which permits use and distribution in any medium, provided the original work is properly cited and no modifications or adaptations are made. View EIX.org Authorship Terms at https://eix.org/terms
FamilyBusiness 
that directly sells to households)?

- The board identifies any opportunities upon which the company can capitalize in the current environment, without violating their moral code (e.g., talent acquisition)?

\section{Stakeholder Philosophy}

- The board agrees on a philosophy regarding how the company treats its people (e.g., layoffs, salary cuts, furloughs, sick leave policies etc.)?

- The board decides on how, and in alignment with key company/family values, central stakeholders like customers and suppliers shall be treated during this crisis (e.g., extended return periods and generous receivables policies for customers, flexible payables policies, depending on the company's ability).

One thing that is often forgotten is that these basic assumptions have long-term consequences. If, for example, the employee or customer-related policies are inconsistent with the values and culture of the company (making you appear overly opportunistic), you will likely spark mistrust, effectively damaging your relationships with your stakeholders.

\section{Ensuring Sufficient and Effective Processes}

Once all the basic assumptions have been defined and agreed upon, the board needs to make sure that the processes inside the company are sufficient for dealing with the crisis.

1. Sharing Information \& Best Practices: $A$ multi-unit company should create crisis teams at both the corporate and unit levels to coordinate information and best practices.

2. Reputation Management: The board makes sure that a process is put in place for monitoring and responding to potential PR/reputational issues. For companies not large enough to hire someone to monitor the media, this task could be assigned to the leadership team. We know of one case where a worker tested positive for coronavirus, and the media caught wind; by the time the company could correct course, customers had already declined deliveries.

3. Health Policies: The board ensures that a group is developed and staffed dedicated to defining, executing and monitoring policies around employee hygiene, working conditions, sending home high-risk employees, or limiting the number of people able to enter certain areas.

4. Monitoring and Adjusting to New Federal, State and Local Laws and Regulations: It is somewhat unfortunate that even when a crisis sows fear and uncertainty, government entities are still changing regulations and laws without ample warning. The board needs to ensure the company has a process to stay aware of changes and respond quickly. Likewise, board members themselves need to informed about the many regulatory and legal changes.

These are but a few areas that might need increased attention; others may arise. All need targeted action.

\section{Monitoring and Driving Progress}

Once a set of plans and measures has been defined to mitigate the crisis, the board has the responsibility to oversee whether adequate progress is being made as events unfold at a rapid pace. Weekly or bi-weekly board phone calls are strongly advised.

1. Measure progress, in particular tracking whether specific plans have been developed, and then continuously monitor whether those plans are being implemented.

2. Encourage senior leadership and appreciate their loyalty and hard work.

3. Make sure activities are coordinated across the entire organization.

4. Receive and discuss reports on employee, customer and supplier issues, and other crisisrelated risks.

5. Closely monitor financial performance, particularly cash flow, and take action as appropriate.

6. Debrief everyone on the measures taken, the results and the progress made so they can learn from it.

The key here is to maintain a flexible mindset, to seek and absorb new information as the situation develops, and to continuously adjust the frame or other elements of the plan as new information unfolds.

\section{Communication}

During a crisis your communication must be timely, 
transparent and appropriate. If you think you are communicating too much, you are doing the right thing.

- Shareholders: The board has a key role in reassuring and communicating with shareholders, either directly or through the CEO.

- Stakeholders: The board can have an important role in reassuring and appreciating employees, either directly or through the CEO. The board should stay in close contact with the CEO to check on employees' emotional state (the primary worry here is about them being burnt out).

- Family: Some family members may not be shareholders, but still affect the attitudes and decisions of the ownership group. They may have questions. The board can alleviate fear and doubt, reassure them and generally help the leadership engage with the larger ownership group.

Staying connected with your key shareholders and stakeholders, and having the appropriate emotional messaging, is key during this challenging time. The variety of technological platforms available today (text, call, Zoom/Skype, email) can be incredibly helpful in achieving these goals.

\section{Worth Remembering}

Before you put your board to work, remind them to consider the following caveats:

\section{Check Your Biases}

One mistake people often make during a crisis is setting their frame based on how they want to treat people. For example, because you may be reluctant to let people go, you might convince yourself that this is a short-term issue, when it very likely is not. The opposite also holds true. If you are more challenging and direct with people, you may be overly tough on others during a crisis, which could backfire.

\section{Encourage Candor}

Make sure that all board members feel confident actively challenging ideas. Without candor and full participation in setting the frame, the business won't make sound decisions or execute them well. For example, if one very vocal or overly emotional board member dominates the group, other board members may be afraid to speak the truth and they may all go along with a bad idea.

\section{Consider a Full Stop}

An axiom of crisis management is that it's like driving into an impermeable wall of fog, an unknown situation into which you have no visibility. The best course of action for assuring survival, and then growth, is to first come to a full stop, and then slowly accelerate to an optimal speed for the situation. For business, this translates into taking the hardships early (laying off employees, cutting customers, and having difficult conversations with financing sources). Then you can manage how you accelerate to a proper organizational tempo and size (for example, hiring people back, expanding operations again, and adding interestbearing debt to the balance sheet). Unfortunately, at times management mistakenly believes that slowing down gradually is the best thing to do. They start with small actions and then increase their intensity and frequency. But disaster can result if they apply the brakes too timidly or too late; they risk cash shortages, technical bankruptcy, and greater future hardships. Not making the tough decisions early also gives employees false hopes and keeps the people you will likely lay off from being able to find new employment in a timely manner.

\section{Be Encouraging}

Because boards tend to have reviewing and accountability functions, the first reaction is often to criticize suggestions brought forth by management. Instead, boards should encourage and approve any proactive initiative taken by management. In a crisis the right timing of acting is more critical than choosing the ways and means. This is especially true when situations are rapidly changing and new actions in all likelihood will happen quickly. And don't forget - the board's role is "nose in, hands out." Don't get too involved in the details.

Remaining calm under fire will help businesses make strong, well-informed and rational decisions, and avoid being rash or emotionally driven. Companies can prevail over adversity if they effectively mobilize their resources (including their boards), if they are openminded enough to continuously challenge their decisions and actions, and if they have authentic, transparent and frequent communication with all their stakeholders. 
